\title{
Redox modulated hydrogelation of a self-assembling short peptide amphiphile
}

\author{
CAO ChangHai ${ }^{1}$, CAO MeiWen ${ }^{1}$, FAN HaiMing ${ }^{1}$, XIA DaoHong ${ }^{1}$, XU Hai $^{*}$ \& LU Jian R $^{2 *}$ \\ ${ }^{1}$ The Centre for Bioengineering and Biotechnology, China University of Petroleum (East China), Qingdao 266580, China; \\ ${ }^{2}$ Biological Physics Group, School of Physics and Astronomy, University of Manchester, Manchester M13 9JP, United Kingdom
}

Received May 12, 2012; accepted August 29, 2012; published online September 25, 2012

\begin{abstract}
Hydrogels resulting from the self-assembly of small peptides are smart nanobiomaterials as their nanostructuring can be readily tuned by environmental stimuli such as $\mathrm{pH}$, ionic strength and temperature, thereby favoring their practical applications. This work reports experimental observations of formation of peptide hydrogels in response to the redox environment. Ac- $\mathrm{I}_{3} \mathrm{~K}-\mathrm{NH}_{2}$ is a short peptide amphiphile that readily self-assembles into long nanofibers and its gel formation occurs at concentrations of about $10 \mathrm{mmol} / \mathrm{L}$. Introduction of a Cys residue into the hydrophilic region leads to a new molecule, $\mathrm{Ac}-\mathrm{I}_{3} \mathrm{CGK}-\mathrm{NH}_{2}$, that enables the formation of disulfide bonds between self-assembled nanofibers, thus favoring cross-linking and promoting hydrogel formation. Under oxidative environment, Ac- $\mathrm{I}_{3} \mathrm{CGK}-\mathrm{NH}_{2}$ formed hydrogels at much lower concentrations (even at $0.5 \mathrm{mmol} / \mathrm{L}$ ). Furthermore, the strength of the hydrogels could be easily tuned by switching between oxidative and reductive conditions and time. However, AFM, TEM, and CD measurements revealed little morphological and structural changes at molecular and nano dimensions, showing no apparent influence arising from the disulfide bond formation.
\end{abstract}

peptide amphiphiles, self-assembly, hydrogelation, redox stimuli

Citation: Cao C H, Cao M W, Fan H M, et al. Redox modulated hydrogelation of a self-assembling short peptide amphiphile. Chin Sci Bull, 2012, 57: 4296-4303, doi: $10.1007 / \mathrm{s} 11434-012-5487-2$

Peptide hydrogels have been actively exploited for a variety of biomedical applications such as cell culture, regenerative medicine, controlled drug and gene delivery [1-15]. Most peptide hydrogels arise from the entanglement of selfassembled nanoobjects such as nanofibers and nanotubes. Peptide self-assembly is driven by the orchestrated interaction of several intermolecular non-covalent forces including hydrogen bonding, $\pi-\pi$ stacking, hydrophobic effect and electrostatic interactions. Environmental stimuli including $\mathrm{pH}$ [16-19], ionic strength and/or metal ions [18,20-22], temperature [23], light [24] and enzyme-triggers [25], provide powerful approaches for modulating hydrogelation. Furthermore, introduction of microenvironment-sensitive amino acid residues into peptide sequences is also an important strategy for controlling peptide self-assembly and hydrogelation [9,26-28].

*Corresponding authors (email: xuh@upc.edu.cn; j.lu@manchester.ac.uk)
Most of the self-assembling peptides, capable of forming nanofiber hydrogels, either carry more than 10 amino acid residues or contain non-amino acid moieties such as 9-fluorenylmethoxycarbonyl and long alkyl groups, which favor the self-assembly and hydrogelation through aromatic stacking and/or hydrophobic interaction. In a recent study, we have designed an ultrashort peptide amphiphile $\mathrm{Ac}-\mathrm{I}_{3} \mathrm{~K}$ $\mathrm{NH}_{2}$, consisting of three consecutive hydrophobic Ile residues and a charged Lys residue, and found that it could readily self-assemble into long nanofibers in aqueous solution [29]. These nanofibers could entangle to form a network, thus reducing the fluidity of solution and finally resulting in hydrogelation at a concentration of $10 \mathrm{mmol} / \mathrm{L}$ $(0.53 \%, \mathrm{w} / \mathrm{v})$. However, rheological measurements indicated that these $\mathrm{I}_{3} \mathrm{~K}$ hydrogels were not very stiff, with storage moduli being some 200-300 $\mathrm{Pa}$ at the frequency range of $0.1-10 \mathrm{~Hz}$. Enhancement or modulation of mechanical properties of hydrogels always favors their practical 
applications. In this work, the Cys residue has been introduced into the Ac- $\mathrm{I}_{3} \mathrm{~K}-\mathrm{NH}_{2}$ sequence at the interface of hydrophobic/hydrophilic residues. Thiol groups can couple to form disulfide bonds which may improve the gelling property [18]. Furthermore, the covalent crosslinking can occur in benign conditions (i.e. air oxidation) without additional chemical agents, which is helpful in preserving the biocompatibility and biodegradability of the system concerned. Additionally, a Gly residue was inserted between Cys and Lys in order to create more space for disulfide bond formation, giving the final target sequence of Ac- $\mathrm{I}_{3} \mathrm{CGK}-\mathrm{NH}_{2}$. For comparison, we have also designed another peptide, Ac- $\mathrm{I}_{3} \mathrm{MGK}-\mathrm{NH}_{2}$, where the thiol group is methylated, thus preventing disulfide bond formation. The chemical structures and space-filling models of the designed peptides are shown in Figure 1.

\section{Materials and methods}

\subsection{Materials}

Protected $L$-amino acids (Fmoc-Ile-OH, Fmoc-Cys(Trt)-OH, Fmoc-Gly-OH, Fmoc-Met-OH and Fmoc-Lys(Boc)-OH), O-Benzotriazole- $N, N, N^{\prime}, N^{\prime}$-tetramethyluronium hexafluorophosphate (HBTU), N-hydroxybenzotriazole (HOBT), $N, N$-diisopropyl ethylamine (DIEA), Trifluoroacetic acid (TFA), Trisopropylsilane (Tis) and MBHA resin were purchased from GL Biochem (Shanghai) Ltd. and used as received. Piperidine, dichloromethane (DCM) and $\mathrm{N}, \mathrm{N}$ dimethyl formamide (DMF) were purchased from Bo Maijie Technology, and were redistilled prior to use. Other regents were obtained from Sigma and used without further purification. Milli-Q water $(18 \mathrm{M} \Omega \mathrm{cm})$ was used for all the experiments.

\subsection{Peptide synthesis}

The peptides were synthesized using the Fmoc solid-phase synthesis strategy from natural $L$-amino acids, on a CEM Liberty microwave peptide synthesizer. As shown in Figure 1 , the $\mathrm{N}$ - and C-termini of the peptides were acetylated and amidated, respectively, to eliminate the effect of terminal charges that are believed to complicate the process of selfassembly. The detailed procedures have been described in our previous work [30-33]. Deprotection, activation, coupling and capping were carried out on the synthesizer and cleavage from the resin was finished manually away from the synthesizer. The cleavage mixture was then filtered into a round-bottomed flask and evaporated to a concentrated solution which was subsequently dropped into cold ether for precipitation. The ether solution was centrifuged at $4^{\circ} \mathrm{C}$ and $7000 \mathrm{r} / \mathrm{min}$ for $10 \mathrm{~min}$ and the solid product was collected. The cold ether precipitation procedure was repeated at least six times and the finally collected product was lyophilized for $2 \mathrm{~d}$. Note that the $\mathrm{Ac}-\mathrm{I}_{3} \mathrm{CGK}-\mathrm{NH}_{2}$ sample was stored in $\mathrm{N}_{2}$ atmosphere after lyophilization. MALDI-TOF (matrix assisted laser desorption ionization time-of-flight) and reverse-phase HPLC analysis indicated the higher purity $(>90 \%)$ of the final products (see Figures S1 and S2 in the Supporting Information for spectra).

\subsection{Sample preparation}

An appropriate amount of peptide was dissolved in air-free Milli-Q water at the desired concentration giving a final $\mathrm{pH}$ of 5-6. After quickly dissolving $\mathrm{Ac}-\mathrm{I}_{3} \mathrm{CGK}-\mathrm{NH}_{2}, 1.0 \mathrm{~mL}$ of
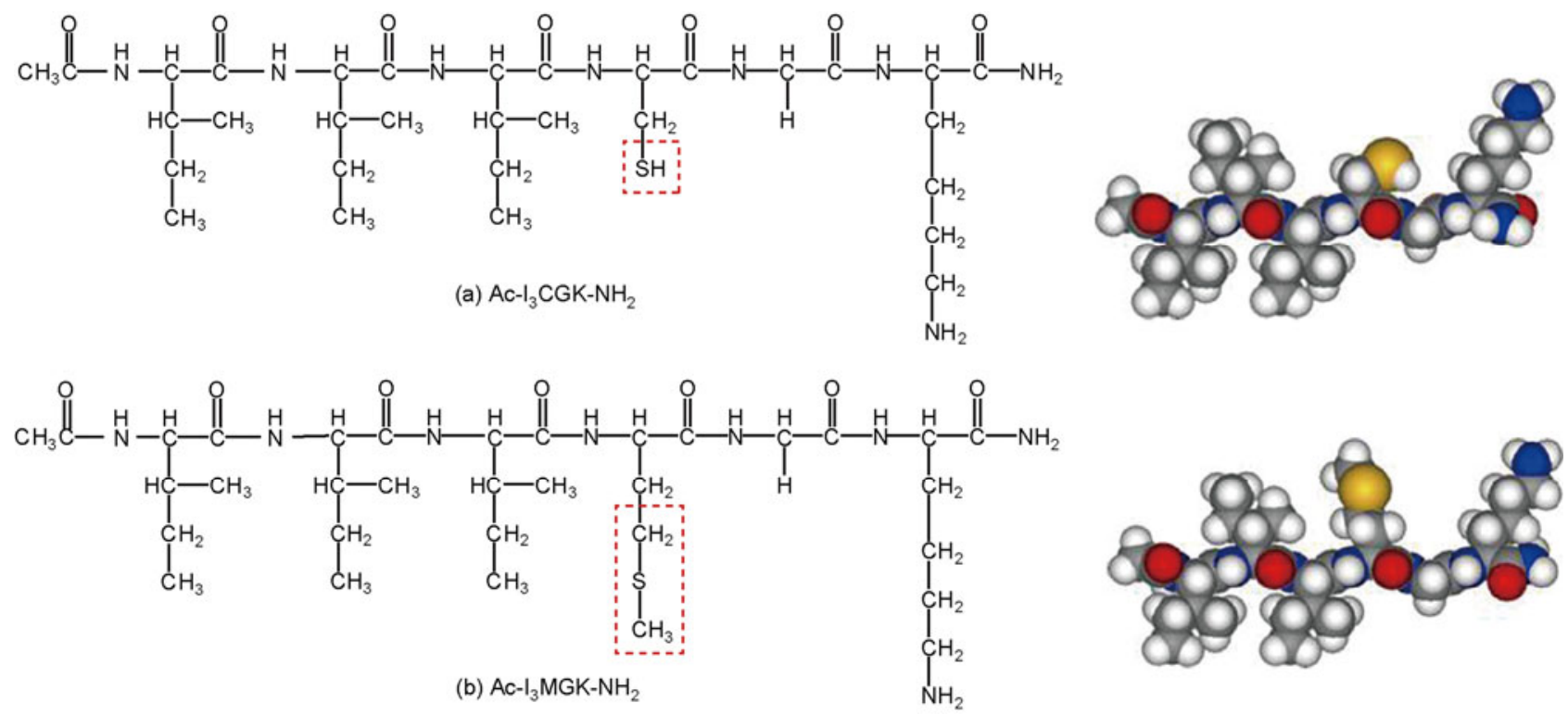

Figure 1 Chemical structures and space-filling models of (a) Ac- $\mathrm{I}_{3} \mathrm{CGK}-\mathrm{NH}_{2}$ and (b) Ac- $\mathrm{I}_{3} \mathrm{MGK}-\mathrm{NH}_{2}$. The red dashed lines highlight the structural differences between the two peptides. Color scheme: carbon (black), hydrogen (white), oxygen (red), nitrogen (blue), and sulfur (yellow). 
the peptide solution was immediately transferred into $8 \mathrm{~mL}$ glass vials (the vial's diameter is $2.0 \mathrm{~cm}$ ), which were then tightly sealed. Thus the upper air space provided the oxygen source for the Cys oxidation. The oxidation time was counted after peptide dissolution. Note that during the oxidation process, no shaking or stirring was performed.

\subsection{Circular dichroism (CD)}

CD spectra were recorded on a Biologic Mos-450/AF-CD spectrophotometer at room temperature using a $0.1 \mathrm{~mm}$ quartz cell. Scans were collected between 190 and $260 \mathrm{~nm}$ in steps of $0.5 \mathrm{~nm}$, with an acquisition time of $2 \mathrm{~s}$. These spectra were averaged and smoothed to improve the signal-to-noise ratio using the software (Bio-kine $32 \mathrm{~V}$ 4.49) supplied by the vendor. The results are here expressed in Millidegree.

\subsection{Attenuated total reflectance-Fourier transform in- frared spectroscopy (ATR-FTIR)}

ATR-FTIR of the peptide solution $\left(1.71 \mathrm{mmol} / \mathrm{L}\right.$ in $\mathrm{D}_{2} \mathrm{O}$ to avoid interference by $\mathrm{H}_{2} \mathrm{O}$ which exhibits strong adsorption near $1640 \mathrm{~cm}^{-1}$ ) was collected at a Nicolet 6700 FT-IR spectrometer equipped with a DTGS detector. An ARK HATR accessory equipped (Thermal Electron) with a $\mathrm{ZnSe}$ crystal and a trough sampling plate was used. The spectra were recorded at room temperature, and 256 scans were measured with a spectral resolution of $4 \mathrm{~cm}^{-1}$ to obtain a good signal-to-noise ratio. Using the OMNIC software package, background and solvent spectra were subtracted and the spectra were smoothed.

\subsection{Rheology}

Rheological measurements were performed on a Physica MCR 301 rheometer (Anton Paar) operating in cone-plate mode (cone angle $1.007^{\circ}$ with diameter of $49.959 \mathrm{~mm}$ ). Peptide samples were transferred to the rheometer stage. After equilibration, dynamic frequency sweep $(0.1-10 \mathrm{~Hz}$ and $0.1 \%$ strain $)$ and dynamic strain sweep $(1 \mathrm{~Hz}$ and $0.01 \%-100 \%$ strain) experiments were performed at $25^{\circ} \mathrm{C}$.

\subsection{Atomic force microscopy (AFM)}

AFM measurements were performed with a commercial Nanoscope IVa MultiMode AFM (Digital Instruments, Santa Barbara, CA) in tapping mode at room temperature. For ambient AFM imaging, $10 \mu \mathrm{L}$ of peptide solution was deposited onto a fleshly cleaved piece of mica. After $2 \mathrm{~min}$, the sample was dried with a gentle stream of nitrogen. Probes used are RTESP silicon probe (Veeco, Santa Barbara, CA) having a typical tip radius of $\sim 10 \mathrm{~nm}$, attached to $125 \mu \mathrm{m}$ cantilevers with a nominal spring constant of 42 $\mathrm{N} / \mathrm{m}$. All images were acquired with a scan speed of $1.0-1.5$
$\mathrm{Hz}$ and at a scan angle of $0^{\circ}$, and flattened using a first-order line fit to correct for piezo-derived differences between scan lines. In each case, topographic and phase images were recorded concurrently, and scans were made at least three times. Representative images are shown here.

\subsection{Transmission electron microscopy (TEM)}

TEM sample preparation was done from peptide solutions using negative-staining. A drop of peptide solution was placed on a 400 mesh copper grid covered by carbonstabilized Formvar film. After $5 \mathrm{~min}$, excess liquid was sucked away by filter paper and the grid was negatively stained with $2 \%$ uranyl acetate aqueous solution. The samples were imaged under a JEOL 1200EX electron microscope operated at $200 \mathrm{kV}$.

\subsection{Ellman test}

The Ellman test was used to determine the amount of thiol groups and is known to work well for small peptide and proteins synthesized through standard solid phase synthetic methods [34]. First, 5,5'-dithio-bis(2-nitrobenzoic acid) (DTNB) stock solution $(50 \mathrm{mmol} / \mathrm{L}$ sodium acetate, 2 $\mathrm{mmol} / \mathrm{L}$ DTNB in $\mathrm{H}_{2} \mathrm{O}$ ) and Tris buffer solution $(1 \mathrm{~mol} / \mathrm{L}$, $\mathrm{pH}$ 8.0) were prepared and refrigerated. To obtain the calibration curve, the standard $\mathrm{H}-\mathrm{Cys}-\mathrm{OH} \cdot \mathrm{HCl}$ solutions were prepared from $0.1 \mathrm{mmol} / \mathrm{L}$ to $2.0 \mathrm{mmol} / \mathrm{L}$. Then $50 \mu \mathrm{L}$ of DTNB solution, $100 \mu \mathrm{L}$ of Tris solution and $840 \mu \mathrm{L}$ of water were put into a cuvette and mixed carefully using a pipette to get the DTNB reagent $(990 \mu \mathrm{L})$, which was scanned by UV spectrophotometer (1700 Pharma Spec, Shimadzu) at $412 \mathrm{~nm}$ to obtain the background spectrum. Then $10 \mu \mathrm{L}$ of $\mathrm{H}-\mathrm{Cys}-\mathrm{OH} \cdot \mathrm{HCl}$ solution (or the standard solutions) was added into the $990 \mu \mathrm{L}$ DTNB reagent, stirred and incubated for $5 \mathrm{~min}$ at room temperature. The solution absorbance at $412 \mathrm{~nm}$ was recorded twice. The calibration curve was obtained by plotting the absorbance value of each H-Cys$\mathrm{OH} \cdot \mathrm{HCl}$ solution as a function of concentration (see Figure $\mathrm{S} 3$ ). For the determination of thiol groups in the $\mathrm{Ac}^{-\mathrm{I}_{3} \mathrm{CGK}-}$ $\mathrm{NH}_{2}$ solution, the same procedure was performed and the thiol concentration was calculated by referring the observed absorbance value at $412 \mathrm{~nm}$ to the calibration curve. Note that because each Ac- $\mathrm{I}_{3} \mathrm{CGK}-\mathrm{NH}_{2}$ molecule carries one thiol group, the determined thiol concentration should be equal to the concentration of Ac- $\mathrm{I}_{3} \mathrm{CGK}-\mathrm{NH}_{2}$.

\section{Results and discussion}

Ac- $\mathrm{I}_{3} \mathrm{~K}-\mathrm{NH}_{2}$ molecules self-assembled in aqueous solution to form long nanofibers that tended to entangle with increasing peptide concentration [29]. At a relatively high concentration of $10 \mathrm{mmol} / \mathrm{L}$, a self-supporting gel formed, but possessed weak mechanical properties with the storage 
modulus $\left(G^{\prime}\right)$ being 200-300 Pa. At lower concentrations typically below $4 \mathrm{mmol} / \mathrm{L}$, peptide solutions were always freely flowing liquids, regardless of incubation time. Upon introduction of a Cys residue, however, $\mathrm{Ac}-\mathrm{I}_{3} \mathrm{CGK}-\mathrm{NH}_{2}$ was found to form a self-supporting hydrogel even at a low concentration of $0.5 \mathrm{mmol} / \mathrm{L}$ after some $40 \mathrm{~d}$ of incubation (Figure 2). The hydrogel, formed at the concentration of $1.71 \mathrm{mmol} / \mathrm{L}$ and after $6 \mathrm{~d}$ of incubation, displayed significantly enhanced mechanical properties, with $G^{\prime}$ values of $\sim 4500 \mathrm{~Pa}$ (Figure 3(a)). Also note that $G^{\prime}$ and $G^{\prime \prime}$ (loss

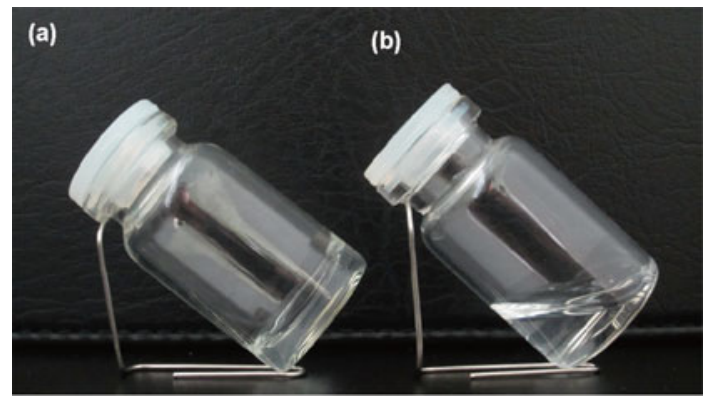

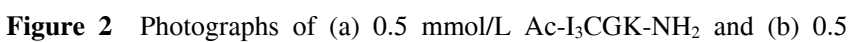
$\mathrm{mmol} / \mathrm{L} \mathrm{Ac}-\mathrm{I}_{3} \mathrm{~K}-\mathrm{NH}_{2}$ after $40 \mathrm{~d}$ of incubation in air.
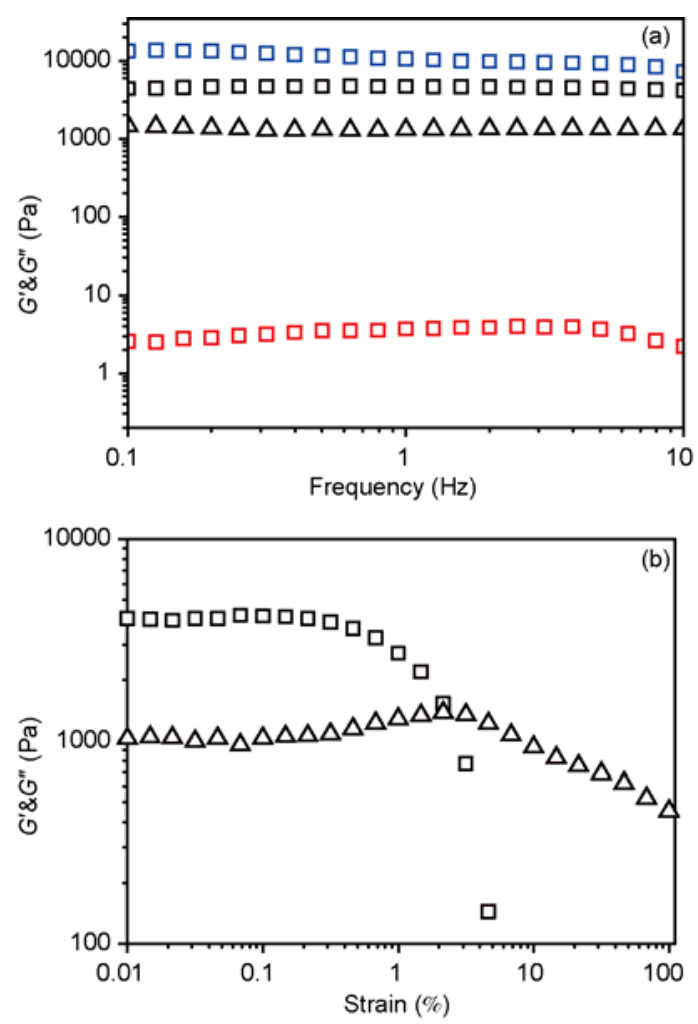

Figure 3 Oscillatory rheological measurements of $1.71 \mathrm{mmol} / \mathrm{L}$ peptide solutions after $6 \mathrm{~d}$ of incubation at different environmental conditions. Storage modulus $\left(G^{\prime}\right.$, square) and loss modulus $\left(G^{\prime \prime}\right.$, triangle) measured with (a) frequency sweeps from $0.1-10 \mathrm{~Hz}$ with $0.1 \%$ constant strain and (b) Strain sweep from $0.01 \%$ to $100 \%$ strain at $1 \mathrm{~Hz}$ oscillation at $25^{\circ} \mathrm{C}$. Color scheme: Ac- $\mathrm{I}_{3} \mathrm{CGK}-\mathrm{NH}_{2}$ (black), Ac- $\mathrm{I}_{3} \mathrm{CGK}-\mathrm{NH}_{2}$ with $\mathrm{H}_{2} \mathrm{O}_{2}$ (blue), and $\mathrm{Ac}-\mathrm{I}_{3} \mathrm{CGK}-\mathrm{NH}_{2}$ with DTT (red). Note that the $G^{\prime \prime}$ values with $\mathrm{H}_{2} \mathrm{O}_{2}$ and DTT are not shown here for clarity. modulus) were frequency insensitive in this frequency range. The vast increase in $G^{\prime}$ and $G^{\prime \prime}$ might arise from the cross-linking of peptide nanofibers through disulfide bond formation. Figure 3(b) shows $G^{\prime}$ and $G^{\prime \prime}$ against strain for the same gel at a $1 \mathrm{~Hz}$ oscillation. Little variation in $G^{\prime}$ and $G^{\prime \prime}$ was observed up to a strain of approximately $1 \%$. A linear viscoelastic regime could thus be ensured for the frequency sweep experiments at a constant strain of $0.1 \%$. Additionally, further increase in peptide concentration shortened gelation time.

To verify this hypothesis, we first examined the effect of addition of reducing agent DTT as it can prevent disulfide bond formation. DTT was added to the aqueous solution immediately after dissolving the peptide at an $\mathrm{Ac}-\mathrm{I}_{3} \mathrm{CGK}$ $\mathrm{NH}_{2}$ /DTT molar ratio of $1: 3$. After $6 \mathrm{~d}$ of incubation, the $1.71 \mathrm{mmol} / \mathrm{L}$ peptide solution containing DTT remained in a free liquid state, and its $G^{\prime}$ values were consistently low (less than $10 \mathrm{~Pa}$ ), which were about 3 orders of magnitude smaller than the values obtained from the system without DTT (Figure 3(a)).

To test the effect of oxidative agent, $\mathrm{H}_{2} \mathrm{O}_{2}$ was used as it exists widely in biological processes. In the first instance, the peptide solution of $1.71 \mathrm{mmol} / \mathrm{L}$ was incubated for $4 \mathrm{~d}$ to ensure the formation of protofibrils, followed by the addition of $\mathrm{H}_{2} \mathrm{O}_{2}$ with an $\mathrm{Ac}-\mathrm{I}_{3} \mathrm{CGK}-\mathrm{NH}_{2} / \mathrm{H}_{2} \mathrm{O}_{2}$ molar ratio of 1:5. On the 6th day, the peptide solution with $\mathrm{H}_{2} \mathrm{O}_{2}$ had $G^{\prime}$ values of $\sim 10000 \mathrm{~Pa}$, an increase by over a factor of 2 over the system without the peroxide (Figure 3(a)). When we substituted DTT for $\mathrm{H}_{2} \mathrm{O}_{2}$ in this process, the peptide solution on the 6th day exhibited $G^{\prime}$ values of $\sim 180 \mathrm{~Pa}$, showing that the clear effect of reduction of the disulphide bonds by DTT as a reducing agent.

Subsequently, we also examined the self-assembly and gelation process by the same amount of $\mathrm{H}_{2} \mathrm{O}_{2}$ added right at the beginning of peptide solution preparation. In this case, the peptide was oxidized to dimers. The self-assembled nanostructures were comprised of spherical stacks and short nanofibers (see Figure S4). The peptide solution did not show any gel-like response, suggesting a distinctly different self-assembling pathway.

The thiol concentration of the peptide solution was monitored using Ellman reagent. Air oxidation is one of the mildest approaches to construct a disulfide bond but usually requires long reaction time [35]. Consistent with this, the thiol concentration decreased gradually over time in the peptide solution in the absence of additional oxidative or reductive agent, as indicated in Figure 4(b). After $6 \mathrm{~d}$ of air incubation, the thiol concentration was reduced from some $1.71 \mathrm{mmol} / \mathrm{L}$ to $0.92 \mathrm{mmol} / \mathrm{L}$, indicating $~ 46 \%$ oxidation, and after $40 \mathrm{~d}$ there was still $\sim 10 \%$ non-oxidized. As indicated by the inset in Figure 4(b), however, the quantity of thiol groups decreased dramatically upon addition of $\mathrm{H}_{2} \mathrm{O}_{2}$ after $4 \mathrm{~d}$ of incubation. In fact, after $6 \mathrm{~h}$ of $\mathrm{H}_{2} \mathrm{O}_{2}$ addition there were few non-oxidized monomers.

Because air oxidation reaction takes place slowly, the 

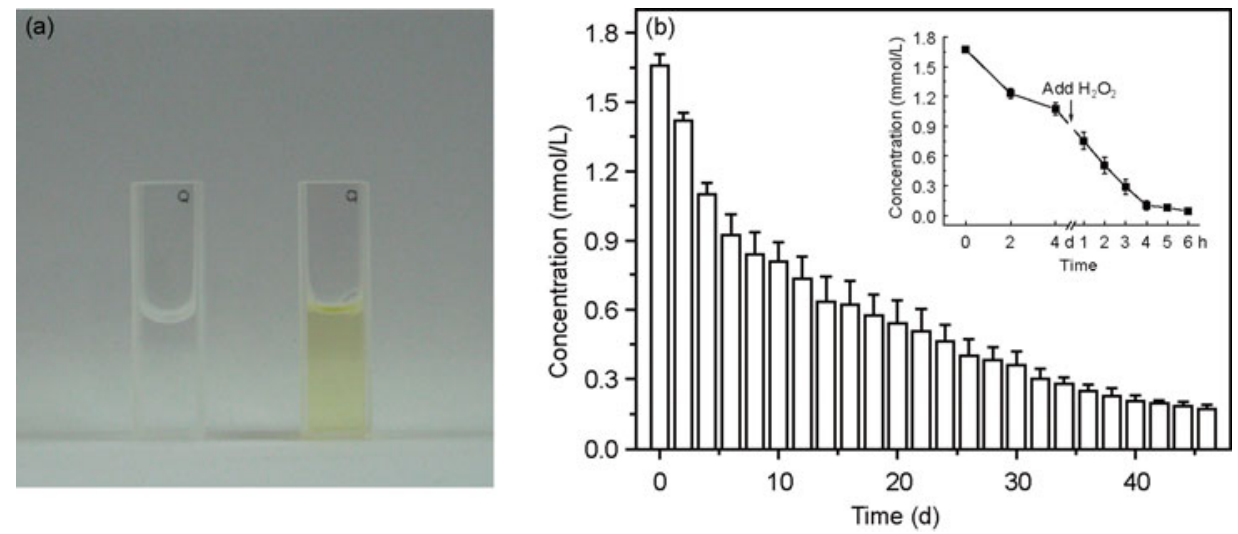

Figure 4 Standard "Ellman Test" for quantitative determination of thiol groups. The original peptide solution was prepared at a concentration of 1.71 $\mathrm{mmol} / \mathrm{L}$. (a) In the presence of thiol groups, colorless DTNB was transformed into yellow 2-nitro-5-thiobenzoic acid (TNB); (b) variation of the Ac- $\mathrm{I}_{3} \mathrm{CGK}-$ $\mathrm{NH}_{2}$ or thiol group concentration over time. The inset shows the decrease in the quantity of thiol groups after addition of $\mathrm{H}_{2} \mathrm{O}_{2}$.

viscoelastic properties of the Ac- $\mathrm{I}_{3} \mathrm{CGK}-\mathrm{NH}_{2}$ gel can be tuned through oxidation time. Prolonging incubation time in air is expected to increase the gel's stiffness. The $G^{\prime}$ values were found to increase to $\sim 15000 \mathrm{~Pa}$ after $25 \mathrm{~d}$ of incubation. There was $24 \%$ non-oxidized monomer at this time point. Besides, the more cross-linking of nanofibers resulting from increased disulfide bond formation, the further physical entanglement of nanofibers with time, leading to the significant improvement in the mechanical strength. On the other hand, because no additional chemicals were needed for air oxidation reaction and the process occurred spontaneously in aqueous solution, the resulting gel would be advantageous for various biomedical applications.

AFM and TEM were utilized to visualize the hydrogel nanostructures (Figure 5). Similar to $\mathrm{Ac}-\mathrm{I}_{3} \mathrm{~K}-\mathrm{NH}_{2}$, Ac$\mathrm{I}_{3} \mathrm{CGK}-\mathrm{NH}_{2}$ also self-assembled into long nanofibers, in sharp contrast to the spherical nanostacks and short nanofibers formed from the oxidized peptide dimers if strong oxidant such as $\mathrm{H}_{2} \mathrm{O}_{2}$ is added right at the beginning of peptide solution preparation. Upon formation of peptide nanofibers, the hydrophilic CGK region is exposed to the outer surface. Subsequent disulfide bond formation helps to crosslink already formed nanofibers into gel network. Thus, such chemical bond connections between the surfaces of nanofibers do not disrupt the morphology of the assembled fibers but instead, increase the connectivity of the nanofiber network (Figure 5).

To evaluate the secondary structures of the peptide assemblies in aqueous solution, $\mathrm{CD}$ measurements were first performed from the $1.71 \mathrm{mmol} / \mathrm{L}$ peptide solution and the result is shown in Figure 6(a). The positive band at $195 \mathrm{~nm}$ and negative band at $220 \mathrm{~nm}$ suggest a typical $\beta$-sheet structure. The two bands intensified dramatically over the first few hours. The $\beta$-sheet content, as indicated by the negative band at $220 \mathrm{~nm}$, tended to equilibration after about $7 \mathrm{~h}$ (the inset of Figure 6(a)). This observation suggested that the protofibrils formed during this period, consistent with the AFM characterization (see Figure S5). The subsequent association and elongation of protofibrils to long and mature nanofibers did not alter the $\beta$-sheet structure. Also, the disulfide bond formation between nanofibers did not affect the secondary structure either. No secondary structural variation was observed after adding $\mathrm{H}_{2} \mathrm{O}_{2}$ into the system, showing that the promotion of disulfide bond formation
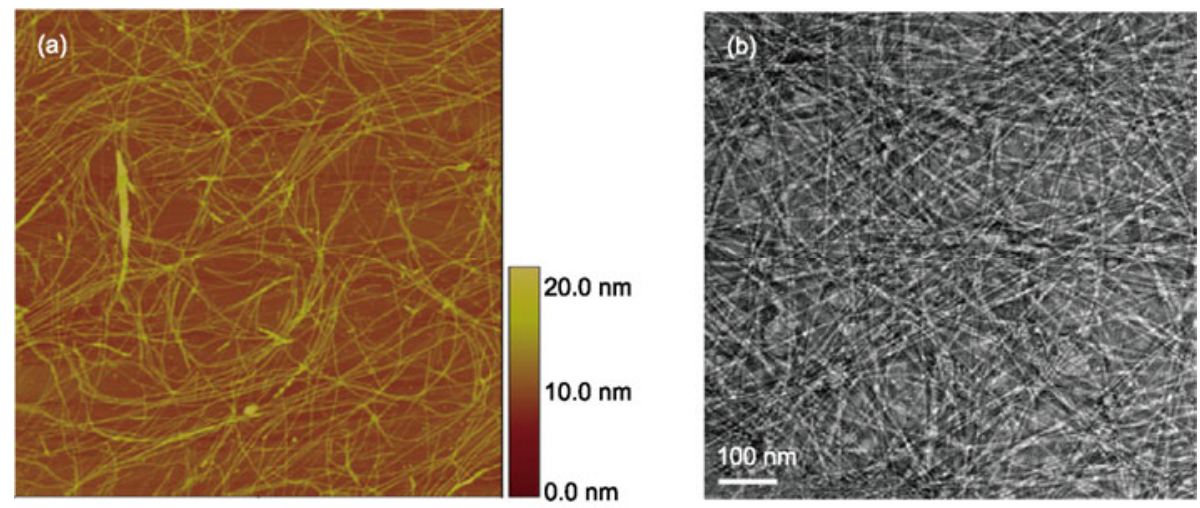

Figure 5 (a) $\mathrm{AFM}(5 \mu \mathrm{m} \times 5 \mu \mathrm{m})$ and (b) TEM images of an $\mathrm{Ac}-\mathrm{I}_{3} \mathrm{CGK}-\mathrm{NH}_{2}$ hydrogel formed at the concentration of $1.71 \mathrm{mmol} / \mathrm{L}$ after $25 \mathrm{~d}$ of incubation in air. The height scale for the AFM image is $20 \mathrm{~nm}$ as indicated. 

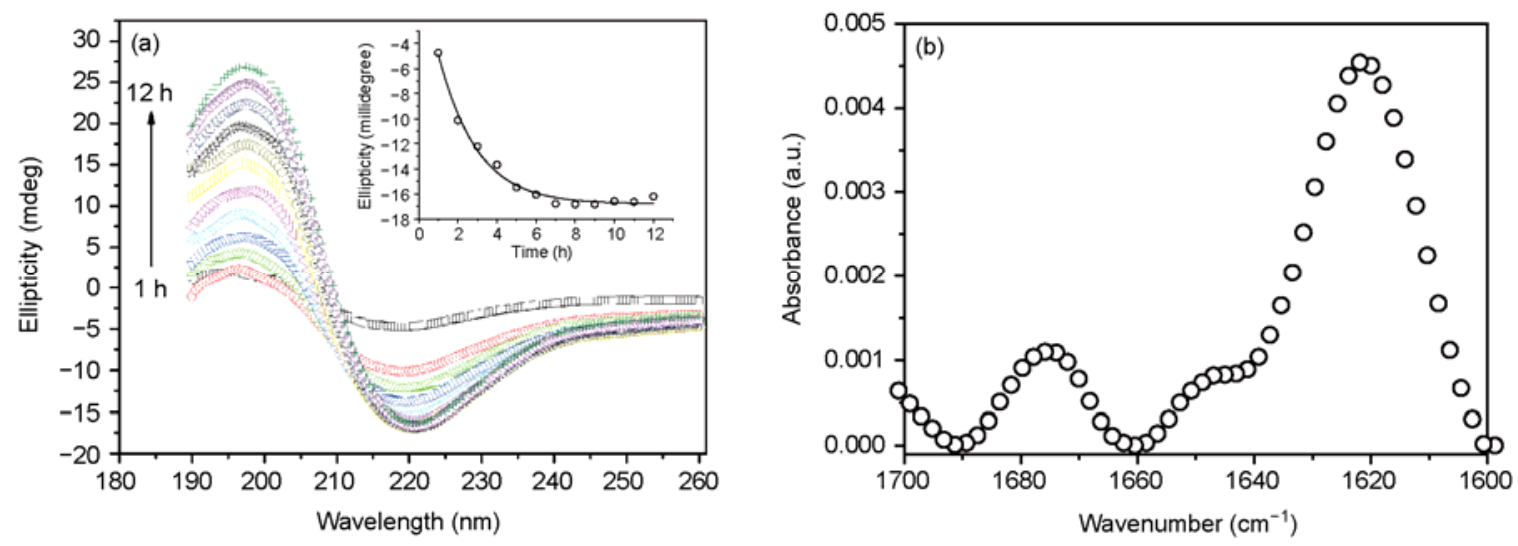

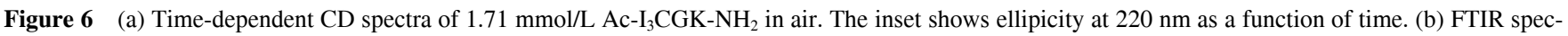

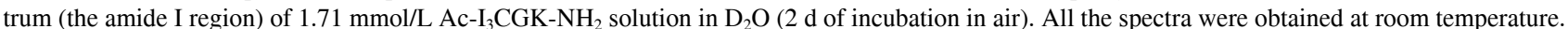

between the nanofibers did not cause detectable changes to the $\beta$-sheet structure (data not shown). Furthermore, complementary FTIR characterizations in $\mathrm{D}_{2} \mathrm{O}$ also indicated the predominance of $\beta$-sheet conformation (Figure 6(b)), where the two peaks centering at 1621 and $1675 \mathrm{~cm}^{-1}$ are indicative of intermolecular anti-parallel $\beta$-sheet structure [36-39].

To further confirm the role of the Cys residue in the hydrogelation and the effect of disulfide bond formation, we designed Ac- $\mathrm{I}_{3} \mathrm{MGK}-\mathrm{NH}_{2}$ in which disulfide bond formation was blocked by methylation. As shown in Figure 7, Ac- $\mathrm{I}_{3} \mathrm{MGK}-\mathrm{NH}_{2}$ assembled into nanofibers and adopted predominantly a $\beta$-sheet structure, but did not form a gel at $1.71 \mathrm{mmol} / \mathrm{L}$ even after $60 \mathrm{~d}$ of incubation. The poor solubility of $\mathrm{Ac}-\mathrm{I}_{3} \mathrm{MGK}-\mathrm{NH}_{2}$ prevented us from evaluating its gelling potential over higher concentrations.

Figure 8 shows a schematic illustration for the Ac$\mathrm{I}_{3} \mathrm{CGK}-\mathrm{NH}_{2}$ gel formation. The peptide molecules firstly assembled into protofibrils by adopting a $\beta$-sheet structure, followed by elongation (end to end) and association (lateral) to long and thick fibers. The Cys residues distributed on the outer surface of the nanofibers are oxidized to disulfide bonds, thus leading to significantly more crosslinking of the nanofibers. This chemical crosslinking, together with physical crosslinking with time, strengthens the interaction between fibers and results in the gelation at much lower concentrations. By controlling oxidation condition, the gelation kinetics and the mechanical properties of $\mathrm{Ac}-\mathrm{I}_{3} \mathrm{CGK}-\mathrm{NH}_{2}$ gels can be tuned in a facile way.

\section{Conclusions}

Ac- $\mathrm{I}_{3} \mathrm{~K}-\mathrm{NH}_{2}$ has been taken as a model sequence into which a Cys residue was introduced in order to demonstrate that incorporation of a chemical crosslinker in the form of the disulfide bond gives a means for controlling gel formation. This work has demonstrated that this facile approach can be generally applied to short self-assembling peptide systems. Redox conditions can be used as a means of controlling the rate and the occurrence of gelation. The realization of this control in hydrogel formation via disulfide bond crosslinking can be used to apply self-assembling peptides in a broad range of biomaterial and biomedical research.
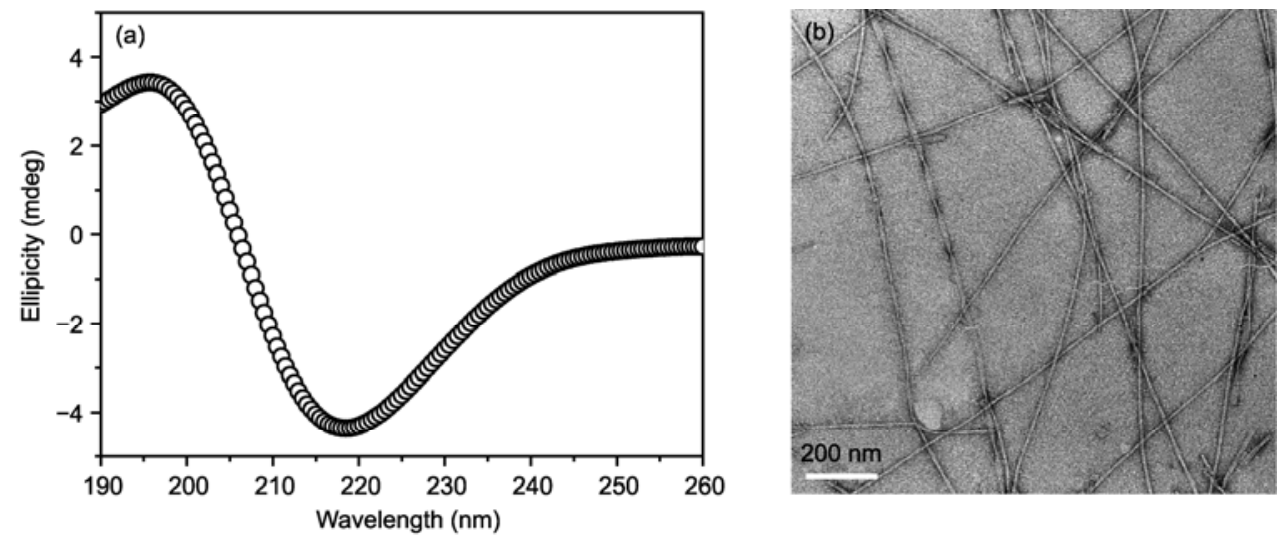

Figure 7 (a) $\mathrm{CD}$ spectrum and (b) TEM image of $\mathrm{Ac}-\mathrm{I}_{3} \mathrm{MGK}-\mathrm{NH}_{2}$ solution at $1.71 \mathrm{mmol} / \mathrm{L}$. 


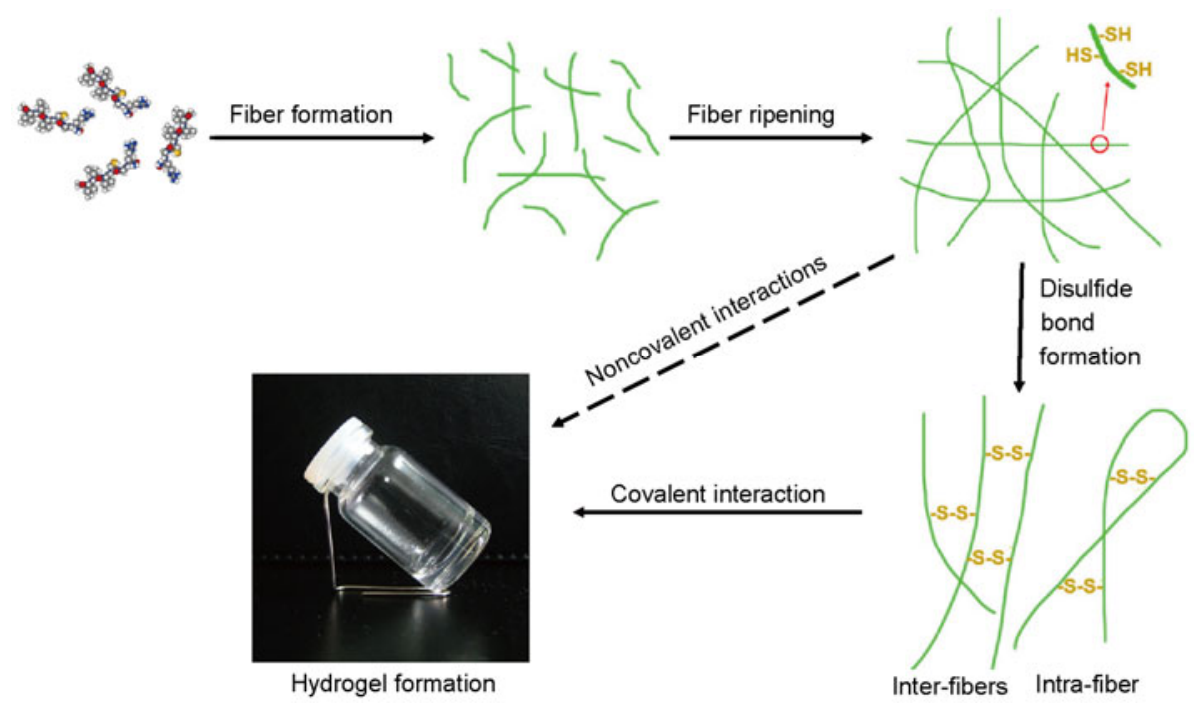

Figure 8 Schematic representation of gel formation. The covalent cross-link between cysteines can form intra- and inter-fiber disulfide bonds, which may function cooperatively with other noncovalent interactions to result in gel formation.

This work was supported by the National Natural Science Foundation of China $(21033005,21003160)$, the Natural Science Foundation of Shandong Province of China (ZR2010BQ003 and JQ201105), and the Innovation Research Program of China University of Petroleum (27R1104067A).

1 Holmes T C, de Lacalle S, Su X, et al. Extensive neurite outgrowth and active synapse formation on self-assembling peptide scaffolds. Proc Natl Acad Sci USA, 2000, 97: 6728-6733

2 Kisiday J, Jim M, Kurz B, et al. Self-assembling peptide hydrogel fosters chondrocyte extracellular matrix production and cell division: Implications for cartilage tissue repair. Proc Natl Acad Sci USA, 2002, 99: 9996-10001

3 Silva G A, Czeisler C, Niece K L, et al. Selective differentiation of neural progenitor cells by high-epitope density nanofibers. Science, 2004, 303: 1352-1355

4 Kretsinger J K, Haines L A, Ozbas B, et al. Cytocompatibility of self-assembled beta-hairpin peptide hydrogel surfaces. Biomaterials, 2005, 26: 5177-5186

5 Beniash E, Hartgerink J D, Storrie H, et al. Self-assembling peptide amphiphile nanofiber matrices for cell entrapment. Acta Biomater, 2005, 1: 387-397

6 Gelain F, Bottai D, Vescovi A, et al. Designer self-assembling peptide nanofiber scaffolds for adult mouse neural stem cell 3-dimensional cultures. PLoS One, 2006, 1: e119

7 Nagai Y, Unsworth L D, Koutsopoulos S, et al. Slow release of moleculesin self-assembling peptide nanofiber scaffold. J Control Release, 2006, 115: 18-25

8 Jayawarna $\mathrm{V}$, Ali M, Jowitt $\mathrm{T}$ A, et al. Nanostructured hydrogels for three-dimensional cell culture through self-assembly of fluorenylmethoxycarbonyl-dipeptides. Adv Mater, 2006, 18: 611-614

9 Haines-Butterick L, Rajagopal K, Branco M, et al. Controlling hydrogelation kinetics by peptide design for three-dimensional encapsulation and injectable delivery of cells. Proc Natl Acad Sci USA, 2007, 104: 7791-7796

10 Jung J P, Nagaraj A K, Fox E K, et al. Co-assembling peptides as defined matrices for entothelias cells. Biomaterials, 2009, 30: 24002410

11 Gelain F, Unsworth L D, Zhang S. Slow and sustained release of active cytokines from self-assembling peptide scaffolds. J Control Release, 2010, 145: 231-239

12 Galler K M, Aulisa L, Regan K R, et al. Self-assembling multidomain peptide hydrogels: Designed susceptibility to enzymatic cleavage allows enhanced cell migration and spreading. J Am Chem Soc, 2010, 132: 3217-3223

13 Williams R J, Hall T E, Glattauer V, et al. The in vivo performance of an enzyme-assisted self-assembled peptide/protein hydorgel. Biomaterials, 2011, 3: 5304-5310

14 Bakota E L, Wang Y, Danesh F R, et al. Injectable multidomain peptide nanofiber hydrogel as a delivery agent for stem cell secretome. Biomacromolecules, 2011, 12: 1651-1657

15 Bulut S, Erkal T S, Toksoz S, et al. Slow release and delivery of antisense oligonucleotide drug by self-assembled peptide amphiphile nanofibers. Biomacromolecues, 2011, 12: 3007-3014

16 Hartgerink J D, Beniash E, Stupp S I. Self-assembly and mineralization of peptide-amphiphile nanofibers. Science, 2001, 294: 16841688

17 Schneider J P, Pochan D J, Ozbas B, et al. Responsive hydrogels from the intramolecular folding and self-assembly of a designed peptide. J Am Chem Soc, 2002, 124: 15030-15037

18 Hartgerink J D, Beniash E, Stupp S I. Peptide-amphiphile nanofibers: A versatile scaffold for the preparation of self-assembling materials. Proc Natl Acad Sci USA, 2002, 99: 5133-5138

19 Rajagopal K, Lamm M S, Haines-Butterick L A, et al. Tuning the $\mathrm{pH}$ responsiveness of $\beta$-hairpin peptide folding, self-assembly, and hydrogel material formation. Biomacromolecules, 2009, 10: 2619-2625

20 Zhang S, Holmes T, Lockshin C, et al. Spontaneous assembly of a self-complementary oligopeptide to form a stable macroscopic membrane. Proc Natl Acad Sci USA, 1993, 90: 3334-3338

21 Ozbas B, Kretsinger J, Rajagopal K, et al. Salt-triggered peptide folding and consequent self-assembly into hydrogels with tunable modulus. Macromolecules, 2004, 37: 7331-7337

22 Micklitsch C M, Knerr P J, Branco M C, et al. Zinc-triggered hydrogelation of a self-assembling $\beta$-hairpin peptide. Angew Chem Int Ed, 2011, 123: 1615-1617

23 Pochan D J, Schneider J P, Kretsinger J, et al. Thermally reversible hydrogels via intramolecular folding and consequent self-assembly of a de novo designed peptide. J Am Chem Soc, 2003, 125: 1180211803

24 Haines L A, Rajagopal K. Ozbas B, et al. Light-activated hydrogel formation via the triggered folding and self-assembly of a designed peptide. J Am Chem Soc, 2005, 127: 17025-17029

25 Toledano S, Williams R J, Jayawarna V, et al. Enzyme-triggered selfassembly of peptide hydrogels via reversed hydrolysis. J Am Chem Soc, 2006, 128: 1070-1071.

26 Caplan M R, Schwartzfarb E M, Zhang S, et al. Control of self- 
assembling oligopeptide matrix formation through systematic variation of amino acid sequence. Biomaterials, 2002, 23: 219-227

27 Bowerman C J, Nilsson B L. A reductive trigger for peptide selfassembly and hydrogelation. J Am Chem Soc, 2010, 132: 95269527

28 Jung J P, Jones J L, Cronier S A, et al. Modulating the mechanical properties of self-assembled peptide hydrogels via native chemical ligation. Biomaterials, 2008, 29: 2143-2151

$29 \mathrm{Xu} \mathrm{H}$, Wang Y M, Ge X, et al. Twisted nanotubes formed from ultrashort amphiphilic peptide $\mathrm{I}_{3} \mathrm{~K}$ and their templating for the fabrication of silica nanotubes. Chem Mater, 2010, 22: 5165-5173

30 Xu H, Wang J, Han S Y, et al. Hydrophobic-region-Induced transitions in self-assembled peptide nanostructures. Langmuir, 2009, 25: 4115-4123

31 Wang J, Han S Y, Meng G, et al. Dynamic self-assembly of surfactant-like peptides $\mathrm{A}_{6} \mathrm{~K}$ and $\mathrm{A}_{9} \mathrm{~K}$. Soft Matter, 2009, 5: 3870-3878

32 Chen C X, Pan F, Zhang S Z, et al. Antibacterial activities of short designer peptide: A link between propensity for nanostructuring and capacity for membrane destabilization. Biomacromolecules, 2010,
11: 402-411

33 Han S Y, Cao S S, Wang Y M, et al. Self-assembly of short peptide amphiphiles: The cooperative effect of hydrophobic interaction and hydrogen bonding. Chem Eur J, 2011, 17: 13095-13102

34 Ellman G L. Tissue sulfhydryl groups. Arch Biochem Biophys, 1959, 82: 70-77

35 Akaji K, Tatsumi T, Yoshida M, et al. Disulfide bond formation using the silyl chloride-sulfoxide system for the synthesis of a cystine peptide. J Am Chem Soc, 1992, 114: 4137-4143

36 Schneider J P, Pochan D J, Ozbas B, et al. Responsive hydrogels from the intramolecular folding and self-assembly of a designed peptide. J Am Chem Soc, 2002, 124: 15030-15037

37 Barth A, Zscherp C. What vibrations tell about proteins. Q Rev Biophys, 2002, 35: 369-430

38 Yan H, Saiani A, Gough J E, et al. Thermoreversible protein hydrogel as cell scaffold. Biomacromolecules, 2006, 7: 2776-2782

39 Krysmann M J, Castelletto V, Kelarakis A, et al. Self-assembly and hydrogelation of an amyloid peptide fragment. Biochemistry, 2008, 47: 4597

Open Access This article is distributed under the terms of the Creative Commons Attribution License which permits any use, distribution, and reproduction in any medium, provided the original author(s) and source are credited.

\section{Supporting Information}

Figure S1 MALDI-TOF mass spectra of (a) Ac- $\mathrm{I}_{3} \mathrm{CGK}-\mathrm{NH}_{2}$ and (b) $\mathrm{Ac}_{3} \mathrm{I}_{3} \mathrm{MGK}-\mathrm{NH}_{2}$.

Figure S2 HPLC profiles of (a) Ac- $\mathrm{I}_{3} \mathrm{CGK}-\mathrm{NH}_{2}$ and (b) $\mathrm{Ac}-\mathrm{I}_{3} \mathrm{MGK}-\mathrm{NH}_{2}$.

Figure S3 The calibration curve of UV absorbance at $412 \mathrm{~nm}$ as a function of $\mathrm{H}-\mathrm{Cys}-\mathrm{OH} \cdot \mathrm{HCl}$ concentration. The linearly dependent coefficient was 0.99989 .

Figure S4 TEM characterization of the self-assembled structures from the oxidized $\mathrm{Ac}_{3} \mathrm{CGK}-\mathrm{NH}_{2}$ dimers.

Figure S5 AFM characterization $(5 \mu \mathrm{m} \times 5 \mu \mathrm{m})$ of protofibrils formed by $\mathrm{Ac}-\mathrm{I}_{3} \mathrm{CGK}-\mathrm{NH}_{2}$ in the first few hours after dissolution.

The supporting information is available online at csb.scichina.com and www.springerlink.com. The supporting materials are published as submitted, without typesetting or editing. The responsibility for scientific accuracy and content remains entirely with the authors. 